\title{
نحو أداة تقنية للتقييم البيئي للتصميم المعماري للمسكن في المناطق الحارة الرطبة
}

بكلية الفنون الجميلة - جامعة المنيا
مدرس بقسم العمارة
د/ ياسر حسن محمود لسرور

yasserssorour@mu.edu.eg

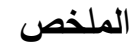

يستهلك قطاع المباني في مصر نسبة كبيرة من إجمالي الطاقة المستهلكة في كافة القطاعات الأخرى، ويأتي استخدام الطاقة

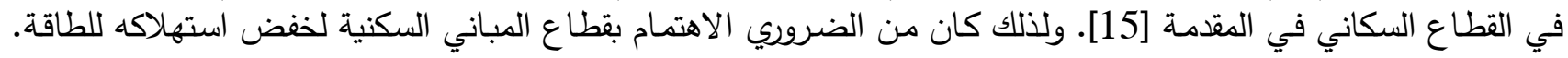

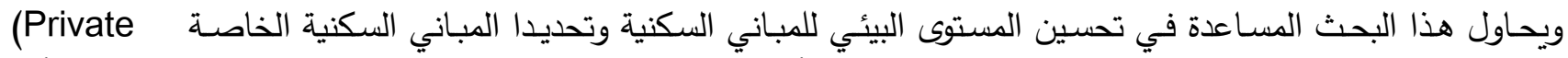
فouses)

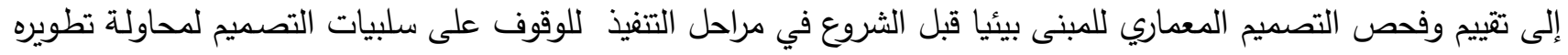

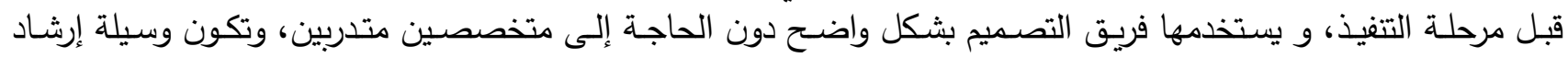

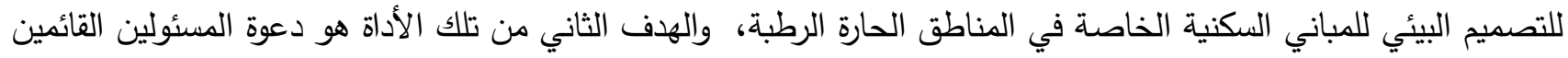

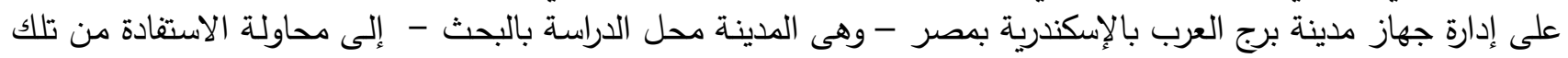

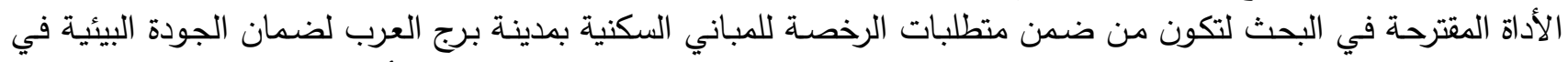

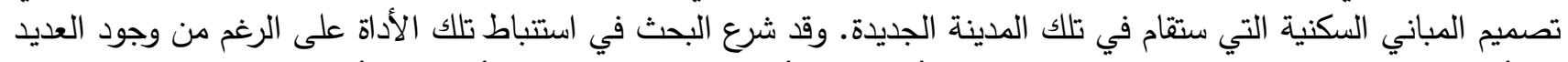

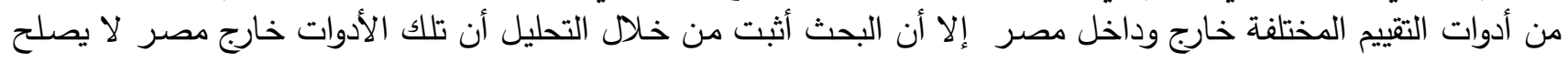

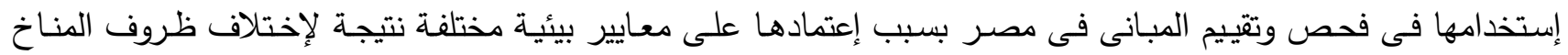

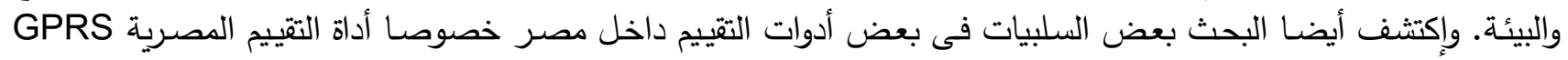

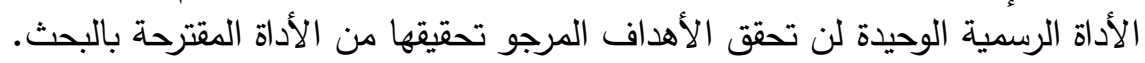

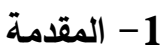

بعد ازدياد أهمية الفكر المستدام في العمارة ازدادت الحاجة إلى أدوات للتيقيم والتصنيف البيئي للمباني ـ مما دفع العديد من ألمان

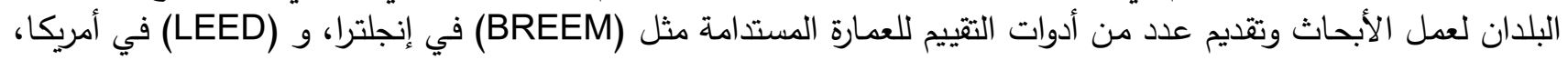

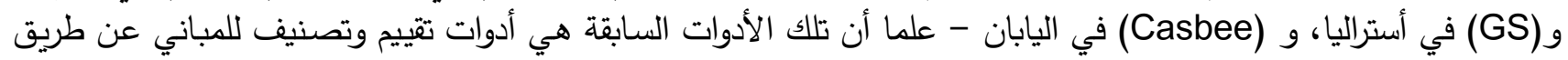

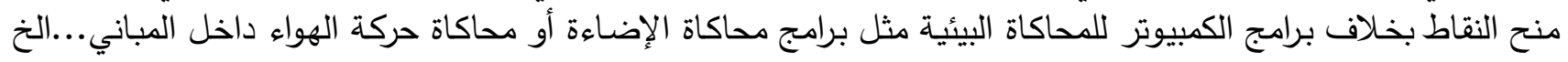

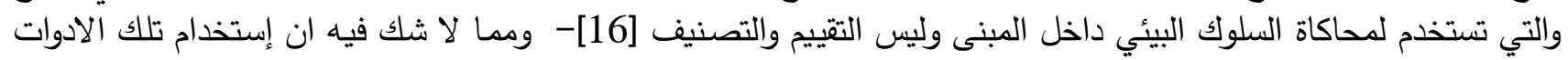

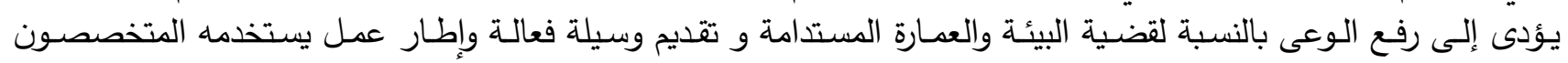

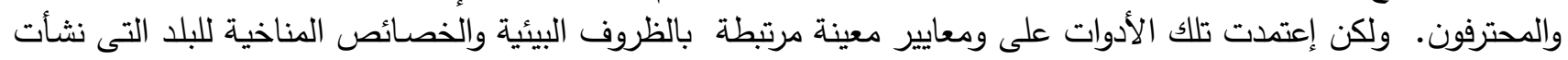

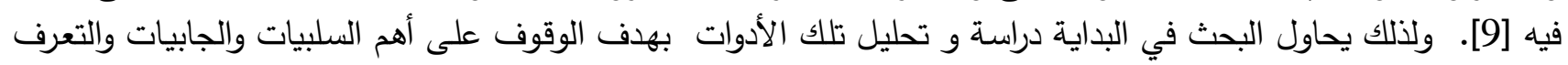

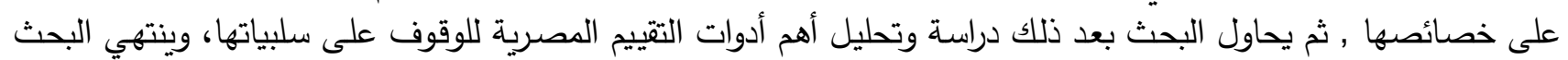

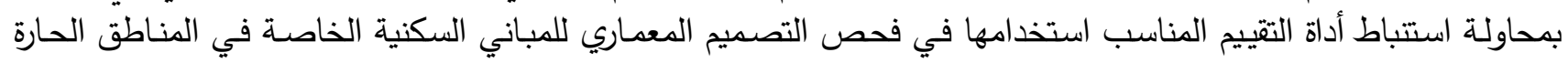
الرطبة في مصر وفقا للمعايير البيئية. 2- الأدوات العالمية للتثييم البيئي للمباني

تعتبر أنظمة التقييم البيئي لكل من Breem, و Leed، و Green Star و و Casbee، هى أهم أدوات التقييم البيئى

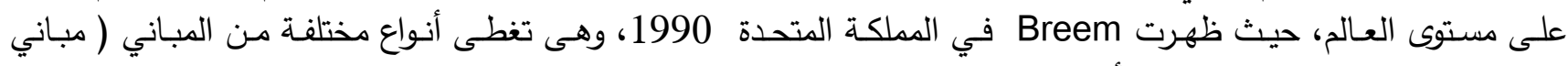

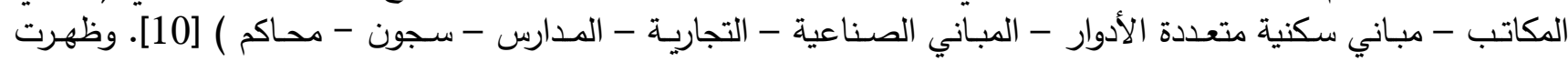

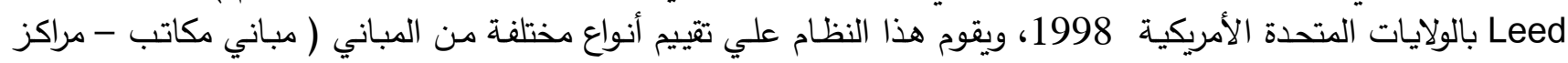

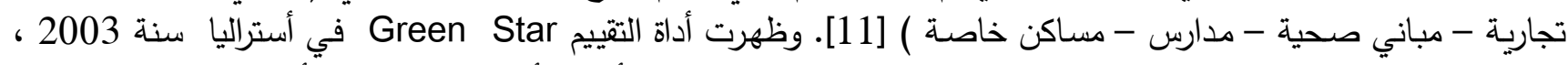

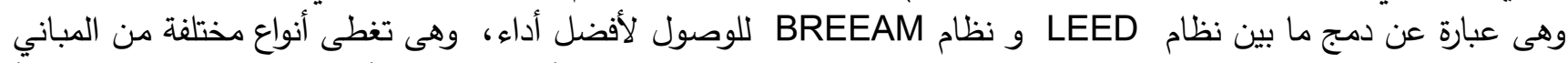

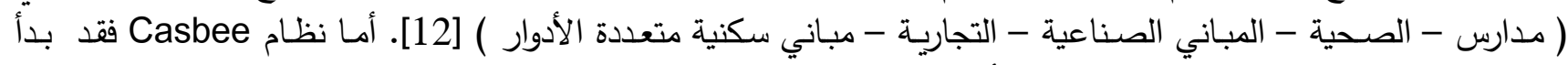

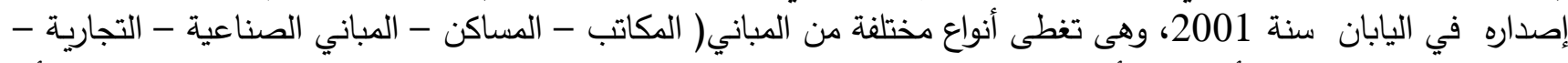

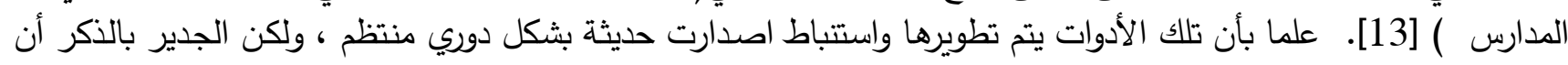


كل من الأدوات الثلاث الأولى تتثابه في اعتمادها على نظام منح النقاط لمجموعة من البنود ثم الخروج بنتيجة التقييم النهائية

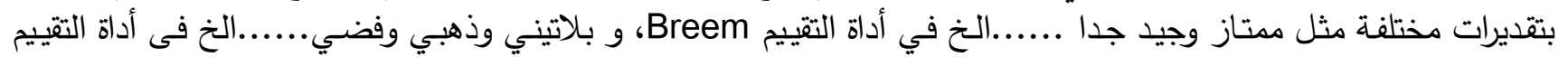

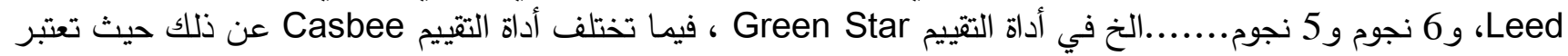

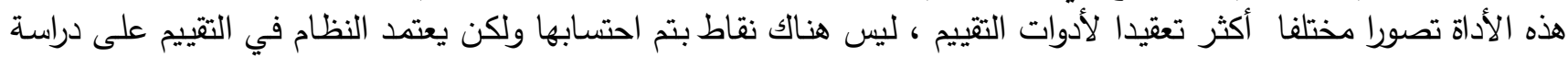

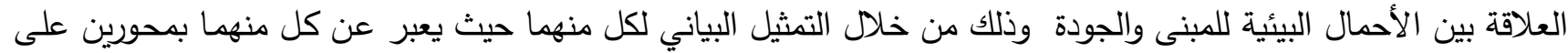

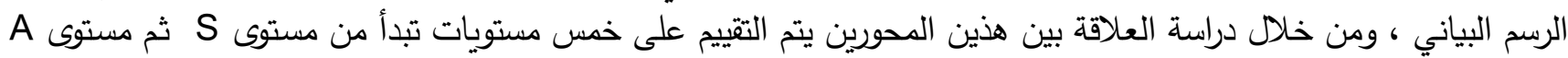
ثم مستوى B+ ثم مستوى -B ثم تتنهي بمستوى C الذي يعبر عن أعلى أحمال بيئية وأقل جودة [5].

$$
\text { 2-2 الملاحـــات : }
$$

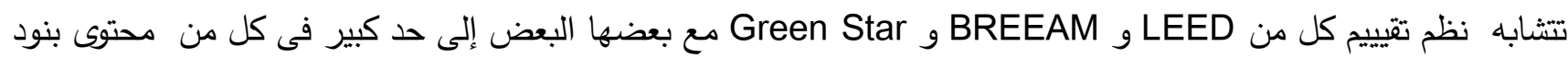

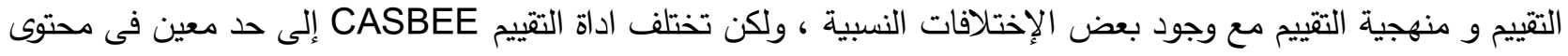
بنود التقييم وتختلف إختلافا جوهريا فى منهجية التقييم.

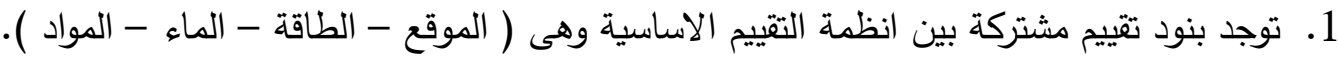

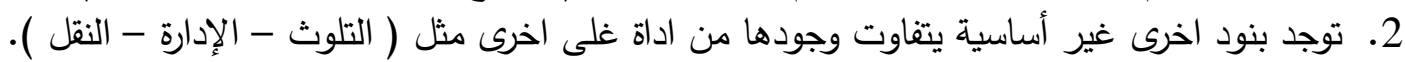

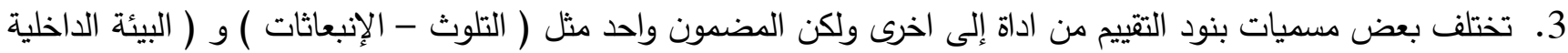

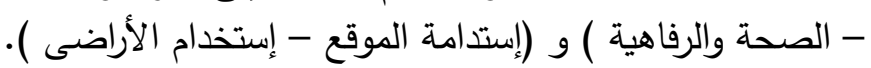

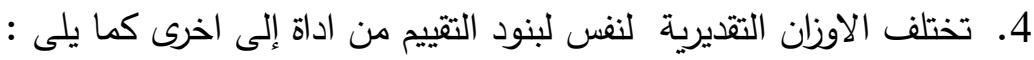

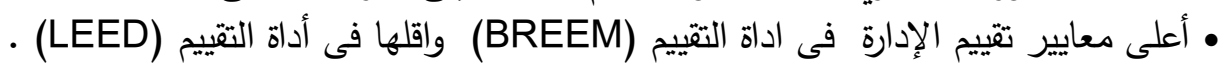

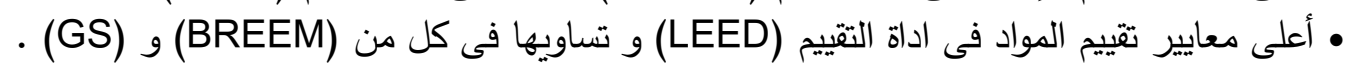

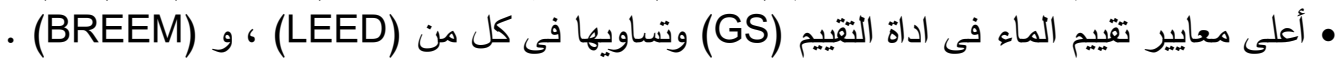

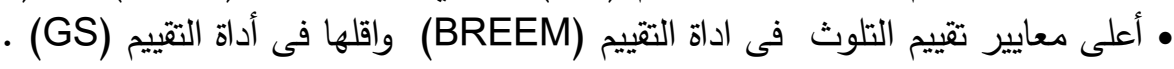

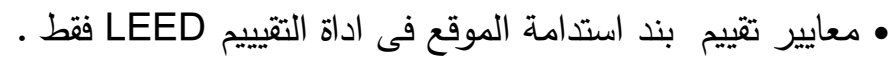
5.

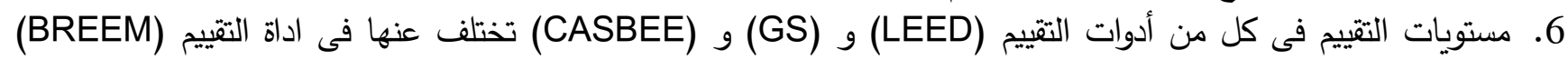

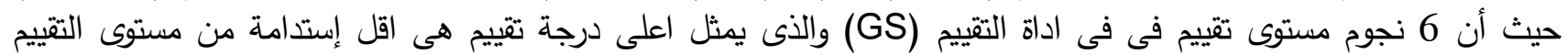

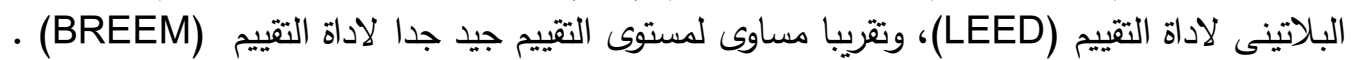

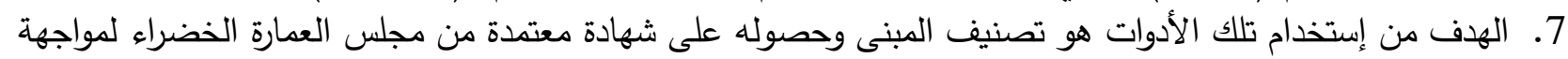
متطلبات السوق • (الباحث)

$$
\text { - :-2-2 }
$$

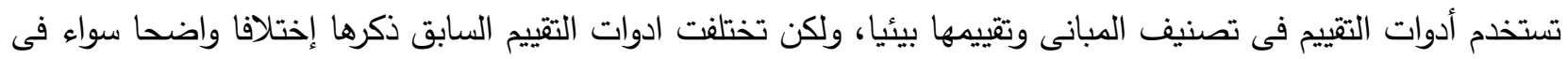

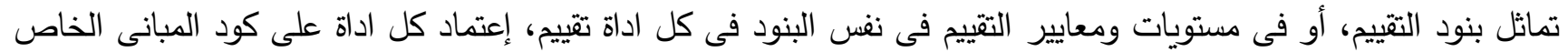

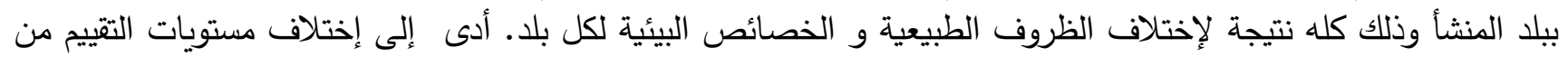

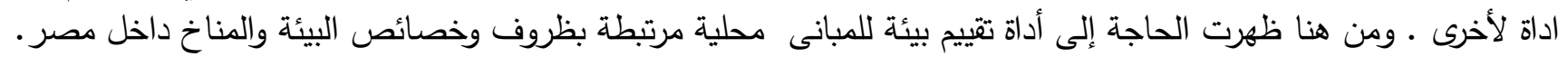

$$
\text { 3- ادوات التقييم داخل مصر }
$$

1-3 - 1-3 منهجية تقييم البعد الإستدامي للمناطق السكنية

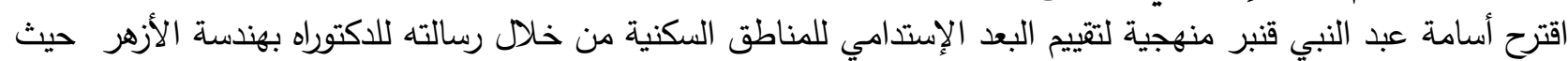

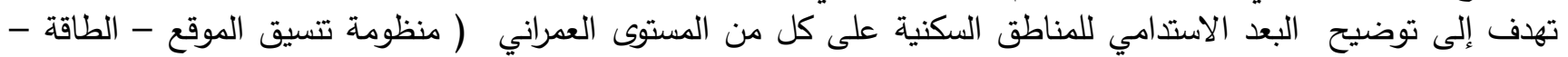

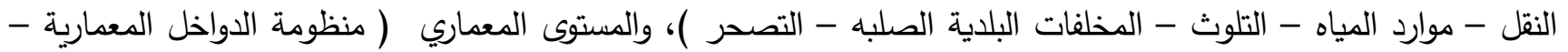

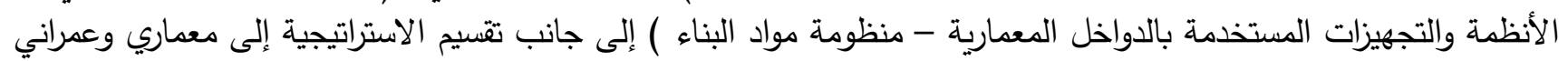

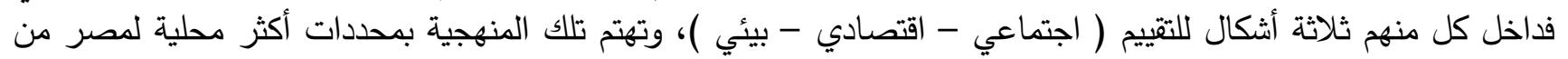
اجل تحقيق الاستدامة من خلال التلوث والتصحر والملوثات [2]. 


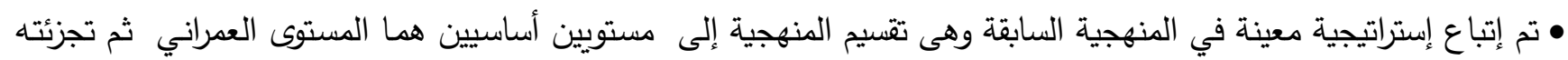

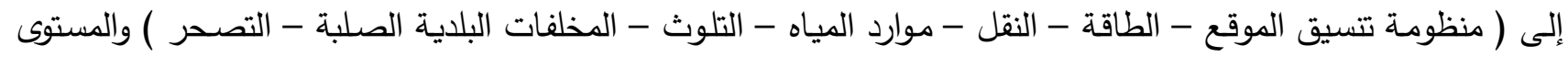

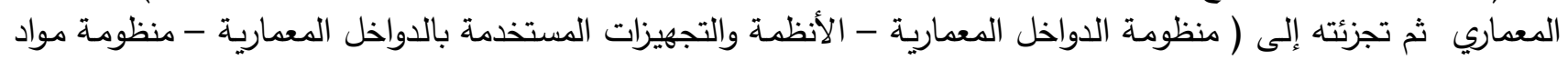

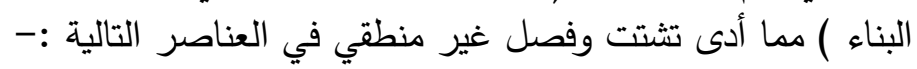

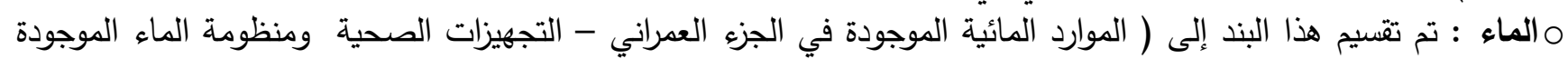

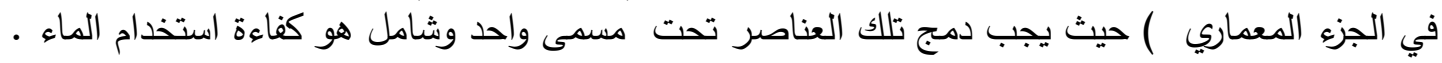

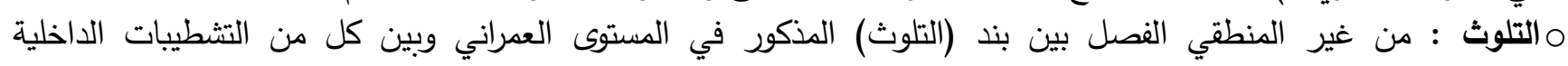

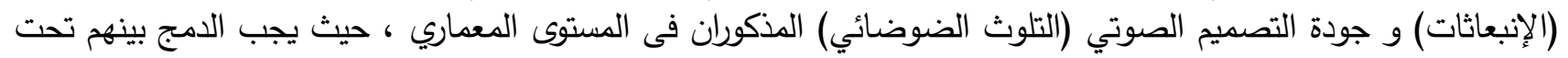
مسمى واحد وشامل وهو التلوث م الطاقة : حيث تم إدراج هذا البند تحت المستوى العمراني وتم تقسيره على أساس استخدام الطاقة المتجددة، ثم تم إدراج بند منظومة الكهرباء تحت المستوى المعماري وتم تفسيره على نفس الأساس وهو استخدام المصادر الطبيعية للكهرباء دون أي مبرر للفصل والتقسيم. متسيق الموقع المذكور تحت المستوى العمراني والبيئة المحيطة المذكورة تحت المستوى المعماري هو مضمون واحد لا يمكن فصله.

• ما هو المبرر ليكون أعلى معدل للنقاط لبند تنسيق الموقع وهو 15 نقطة وأقلها لبند الطاقة وهو 9 نقاط.

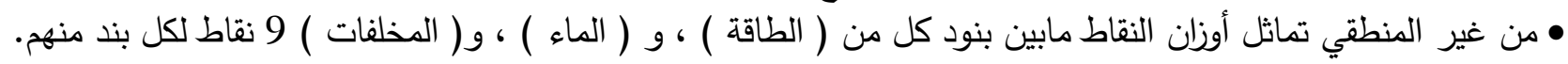

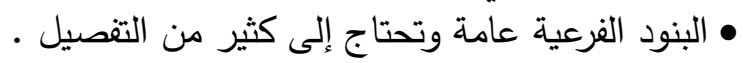

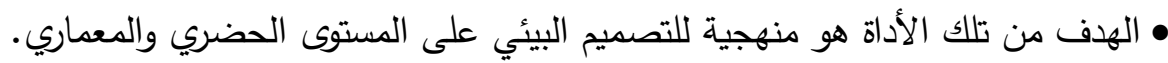

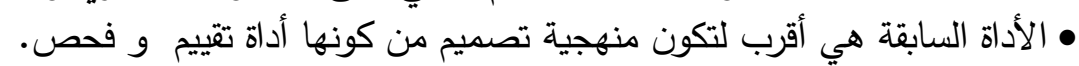

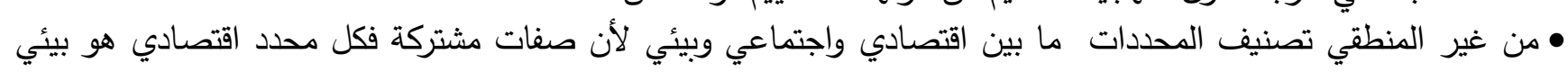

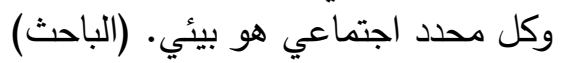

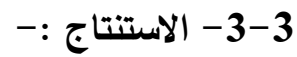

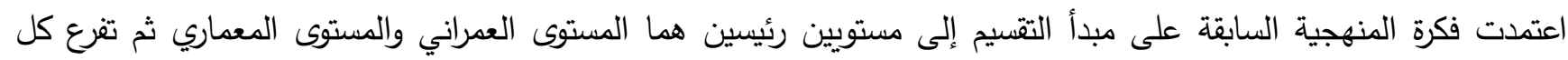

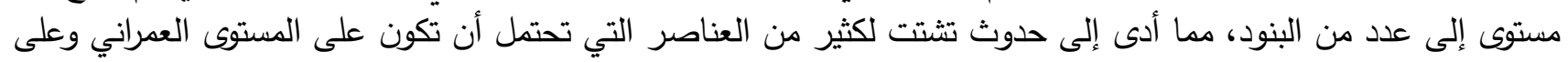

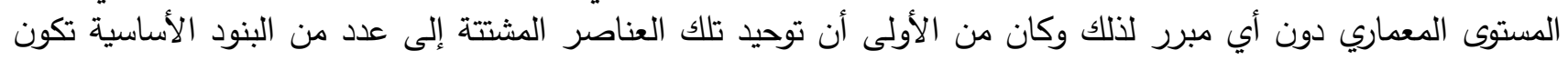

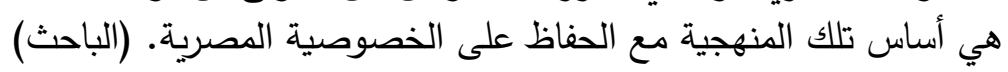

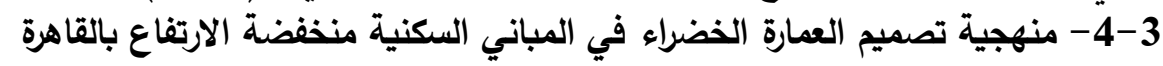
أقترح أسامة السعيد أحمد منصور في رسالته للدكتوراه ( نحو الوصول إلى منهجية لتصميم العمارة الخضراء في التصائه المباني السكنية

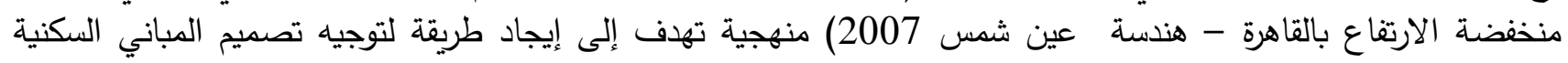

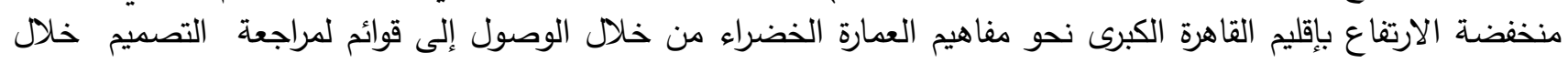

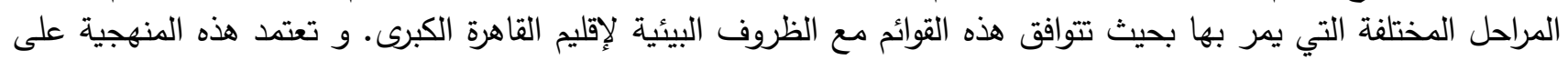

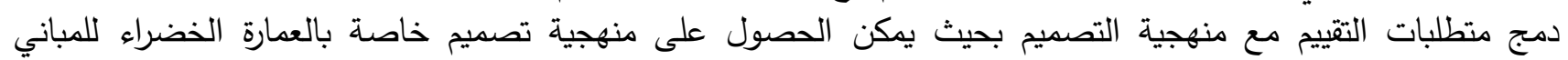

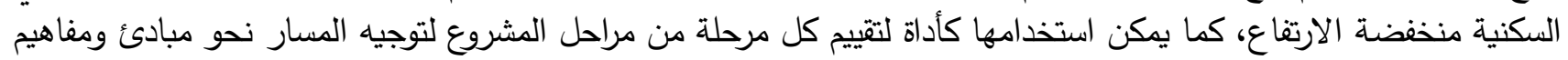

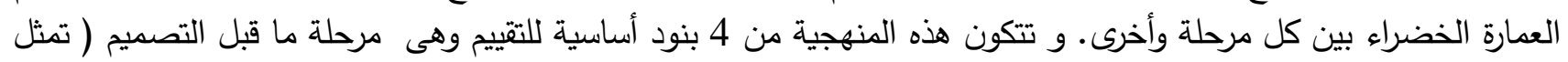

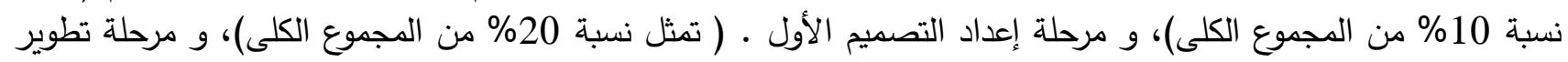

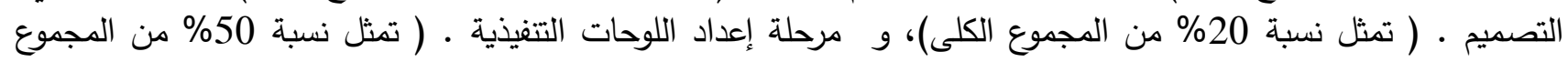
الكلى) على أن تكون نعم = 1 ولا = صفر تصنة ومن خلال مجموع النقاط يتم حساب النسبة الكلية [3].

$$
\text { 3-3-3 - (الملاحظات: - }
$$

• تختص أداة التقييم السابقة بتقييم التصميم المعماري للمباني السكنية منخفضة الارتفاع في إقليم القاهرة الكبرى قبل التنفيذ من خلال تقييم مرحلة ما قبل التصميم ثم تقييم مرحلة إعداد التصميم الأولى ثم تقييم مرحلة تطوير التصديم ثلثيم ثم تقييم مرحلة إعداد اللوحات التنفيذية . • تم تحديد نسب معينة كوزن لكل مرحلة من مراحل التقييم السابقة دون توضيح السبب في اختلاف تلك النسب. 
• النقاط الفرعية المتفرعة من البنود السابقة عامة وتكاد تكون عناوين رئيسية وتحتاج إلى مزيد من التفاصيل لتمكن من عملية

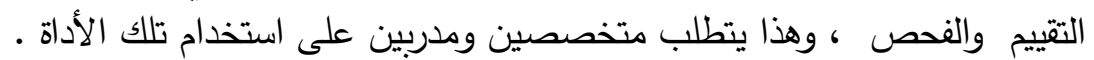
• الأداة السابقة هي اقرب إلى أن تكون كمنهج عام للتصميم منها كأداة للتقييم • (الباحث)

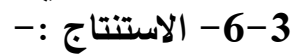

تعتبر أداة التقييم السابق ذكرها هي ملخص جيد للمنهج التصميمي المقترح بالبحث تقوم بإرشاد فريق التصميم أثناء عملية

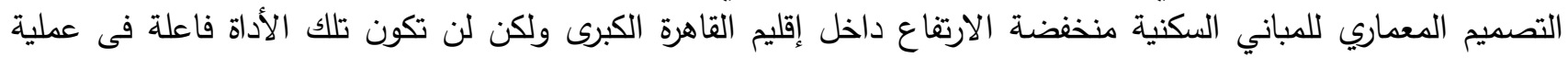

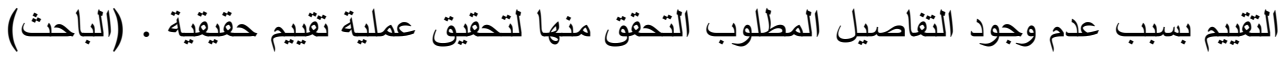

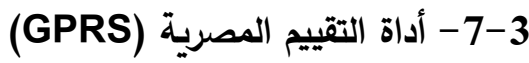

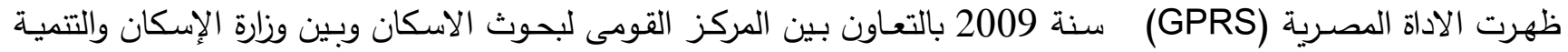

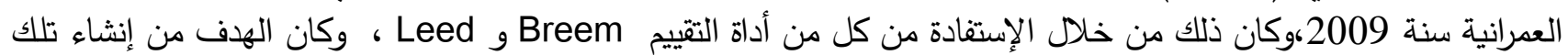
الأداة ان تكون مؤشر لتصنيف المبانى بيئيا فى مصر ، وتكون وسيلة مساعدة للمصمدين والمقاولين والمستشمرين من إتخاذ

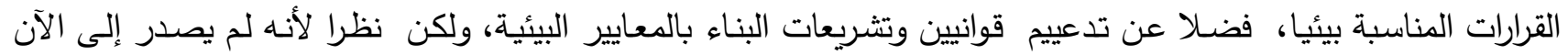

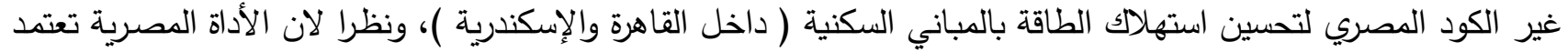

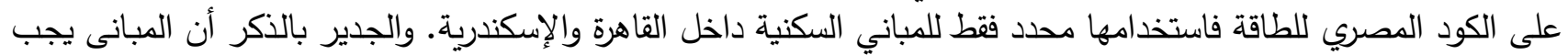

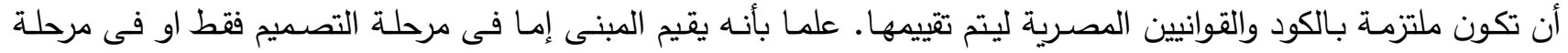

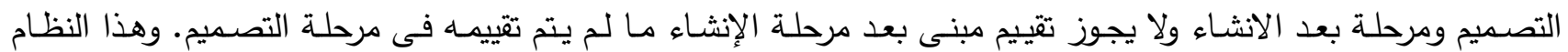

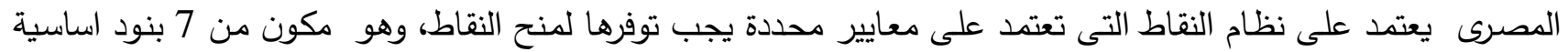

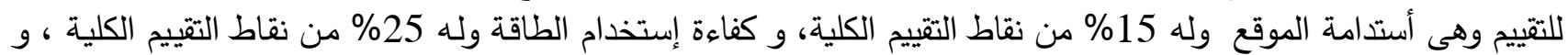

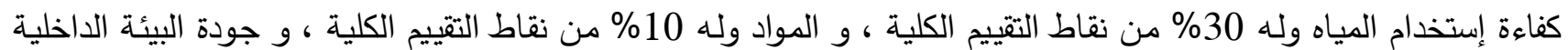

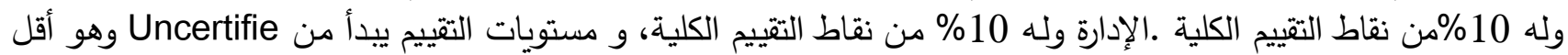

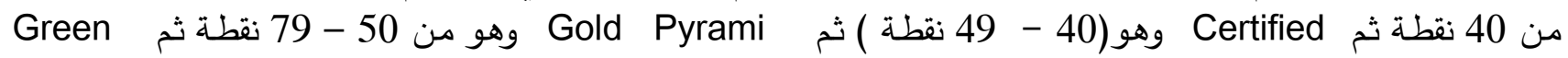
Pyramid وهو من 80 إلى اعلى، وتتم عملية التقييم بالتعاون بين اللجنة العليا ومجموعة من المقيمين المعتمدين ذو الخبرة

اعتمد التقييم في تلك الأداة على الرجوع لموسدة كود الطاقة المصري وهو نظام غير مبسط بالقدر الكافي من حيث شرح

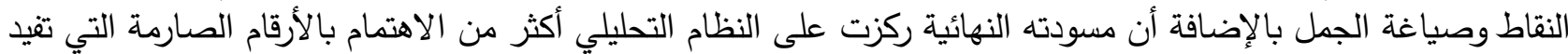

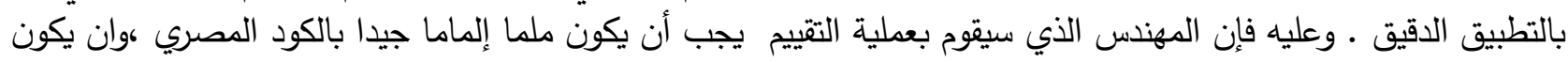

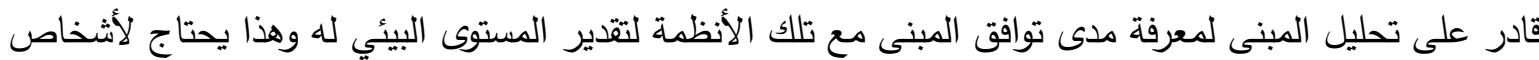

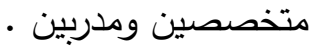
• بند كفاءة استخدام الطاقة على سبيل المثال لا الحصر يتكون من نقاط تقييم تشمل التصميم المعماري والتصميم

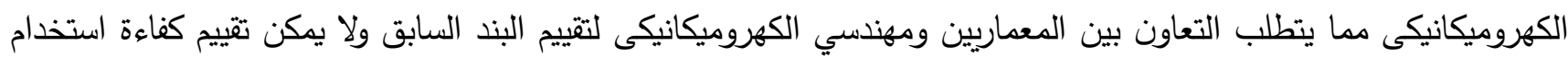

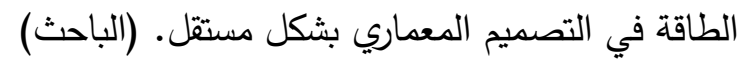

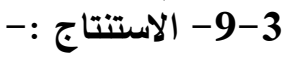

أداة التقييم المصرية هي الوسيلة الرسمية الوحيدة لتصنيف المباني بيئيا داخل مصر ، وهي تعتبر كيان يجمع مابين أداة

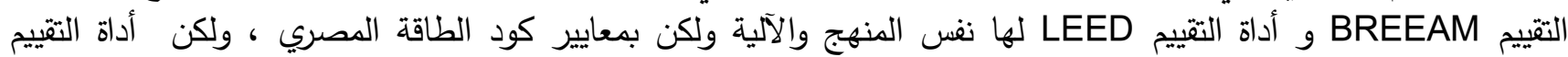
المصرية لن تحقق الهدف من البحث وهو أداة للتقييم البيئي خاصة بتقييم التصميم المعماري فقط قبل مرحلة التنفيذ تكون

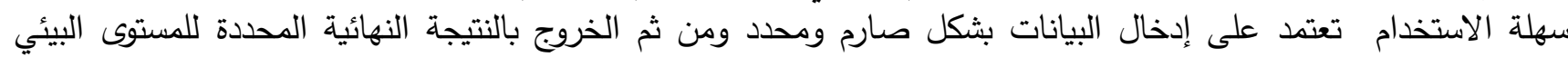
للتصميم المعماري.فأداة التقييم المصرية تعتمد على الرجوع إلى مسودة الكود المصري لكفاءة استخدام الطاقة بالمباني السكنية

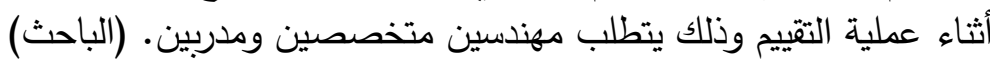
4 - المعايير البيئية في تصميم المسكن فى المناخ الحار الرطب

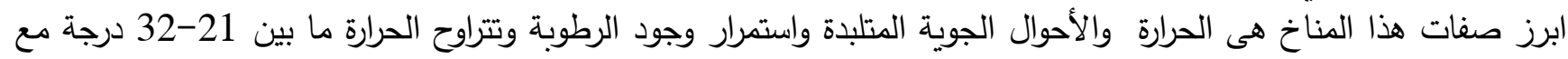

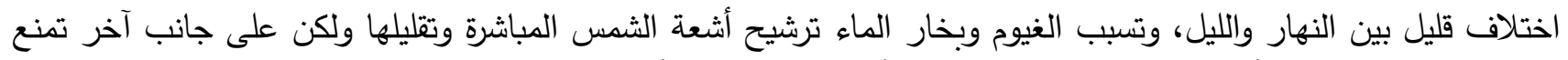
تسرب الإشعاع من الأرض ليلا. وتتلخص بإيجاز أهم السياسات والأهداف في المعالجة البيئية في ذلك المناخ كما هو 
موضح في شكل (1) في إزالة الهواء المشبع ببخار الماء المحيط بالجسم بواسطة حركة الهواء ليسهل عملية تحقيق الراحة

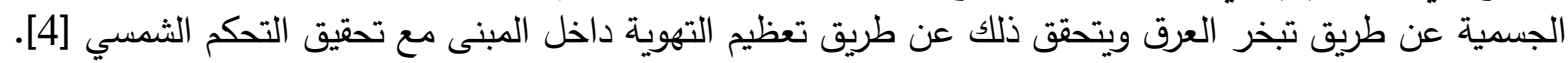

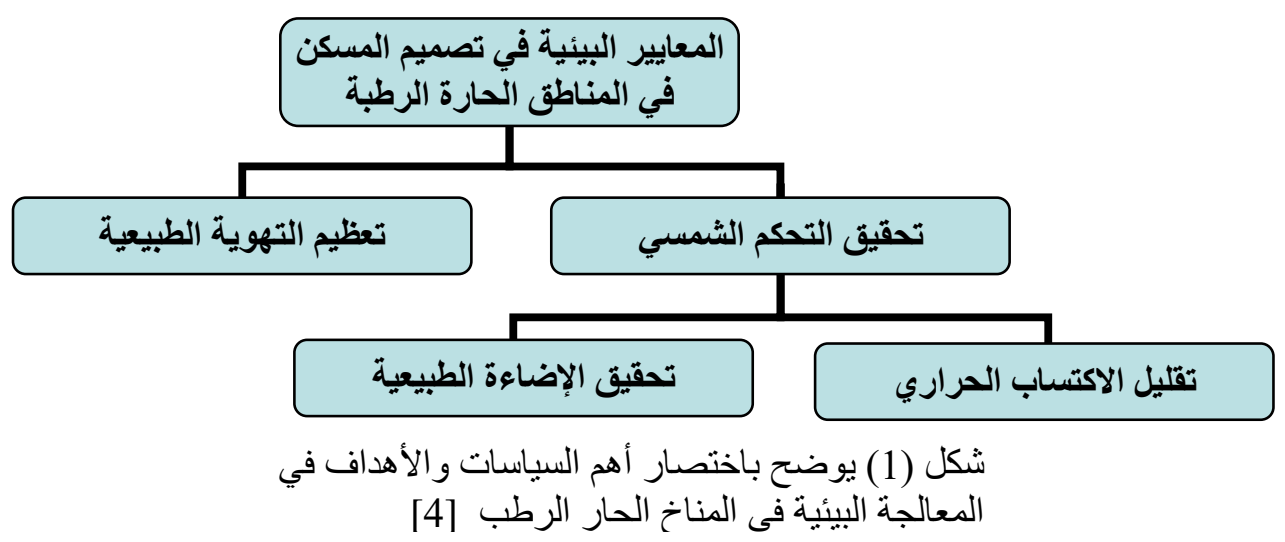

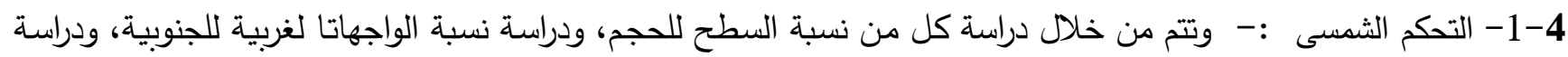
الثكل الهندسى للمسقط الأفقى، ودراسة الثكل الهندسى للقطاع [1]. . و دراسة المواد ونمط إنشاء الغلاف الخارجى للمبنى

4-2- الإضاءة الطبيعية :- وتتحقق من خلال دراسة الثكل الهندسى للمسقط الأفقى، و دراسة تأثير الأفنية، ودراسة التوجيه،

ودراسة الفتحات [6] -

4-3- التهوية الطبيعية :- دراسة الثكل الهندسي للمسقط الأفقي والقطاع، و دراسة تأثير الأفنية، و دراسة الفتحات [7] ـ

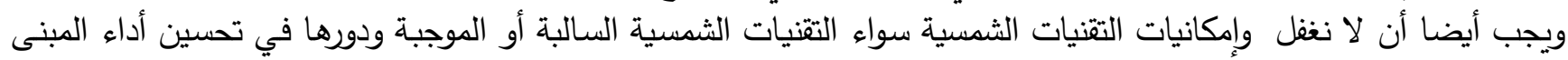

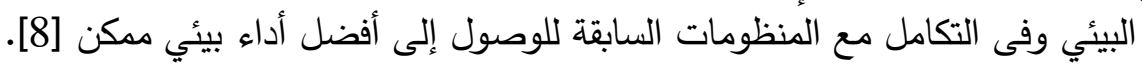

5- أداة التقييم المقترحة :-

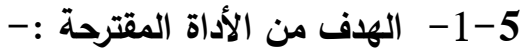

•وسيلة و أداة لفحص التصميم المعماري بيئيا للمباني السكنية الخاصة (Private Houses) في المناطق الحارة الرطبة يستخدمها المعماري لتيقييم المبنى في مرحلة التصميم المعماري - وهى إحدى مراحل دورة حياة المبنى - للوقوف على سلبياته

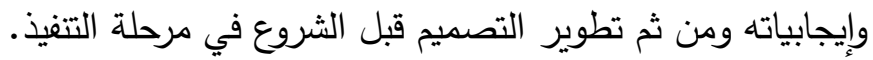

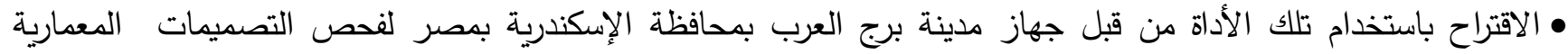
المقدمة للحصول على رخصة البناء بحيث يكون أحد متطلبات الرخصة هو تلإن تحقيق المبنى لحد أدنى معين من المعايير البيئية بالقياس على تلك الأداة.

- -5

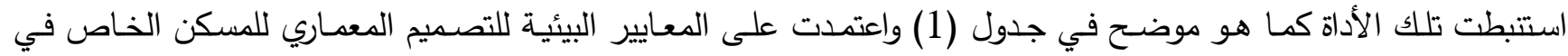

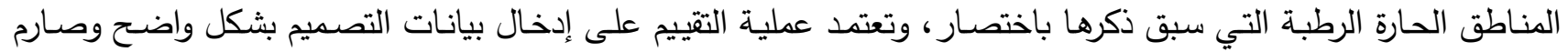

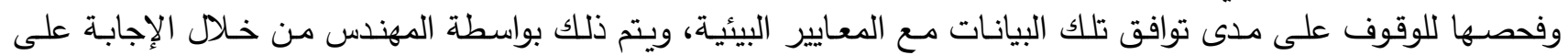

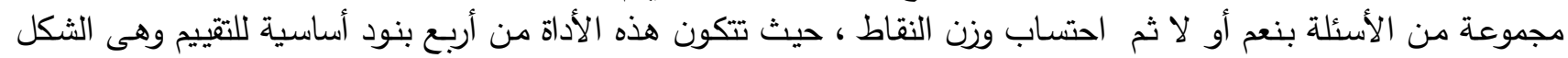

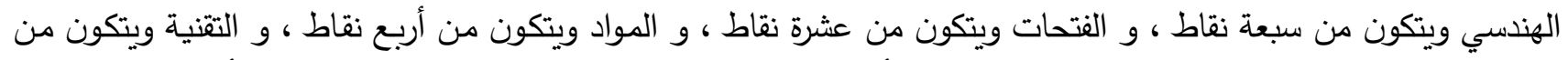

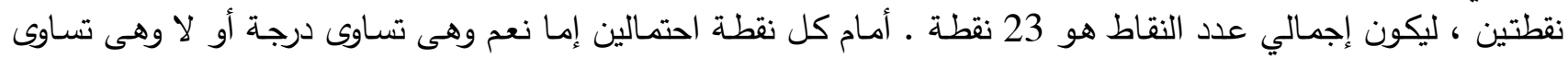

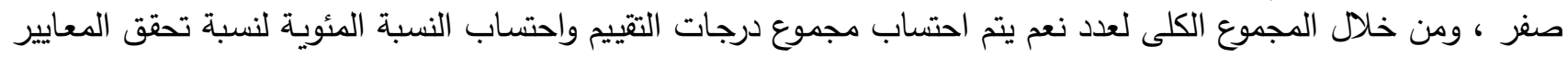
بالمبنى المراد فحصن. 5-3- اداة التثييم التقنية المقترحة فئه

جدول (1) أداة التقييم المقترحة بالبحث (الباحث)

\begin{tabular}{|c|c|c|c|c|}
\hline & & & الموقع : & المششوع : \\
\hline & & & المالك : & المعماري : \\
\hline & & نتيجة التئ & 年 & \\
\hline ע & نعم & بنود التقييم & لنقاط ، حيث تتكون هذه الأداة من & تعتمد الأداة \\
\hline & & الثكل الهندسي & الهندسي ويتكون من سبعة نقاط ، و & أربع بنود \\
\hline
\end{tabular}




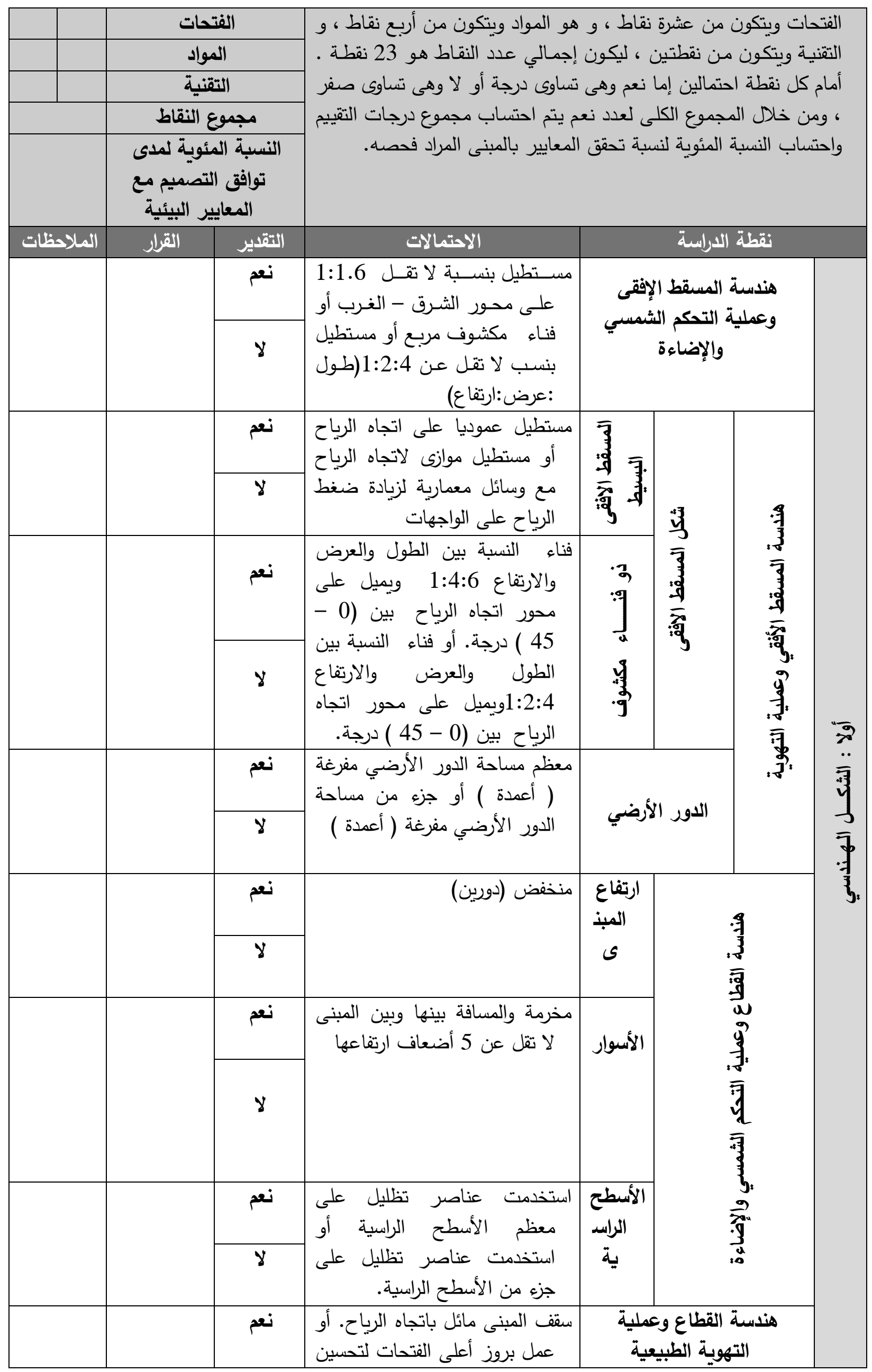




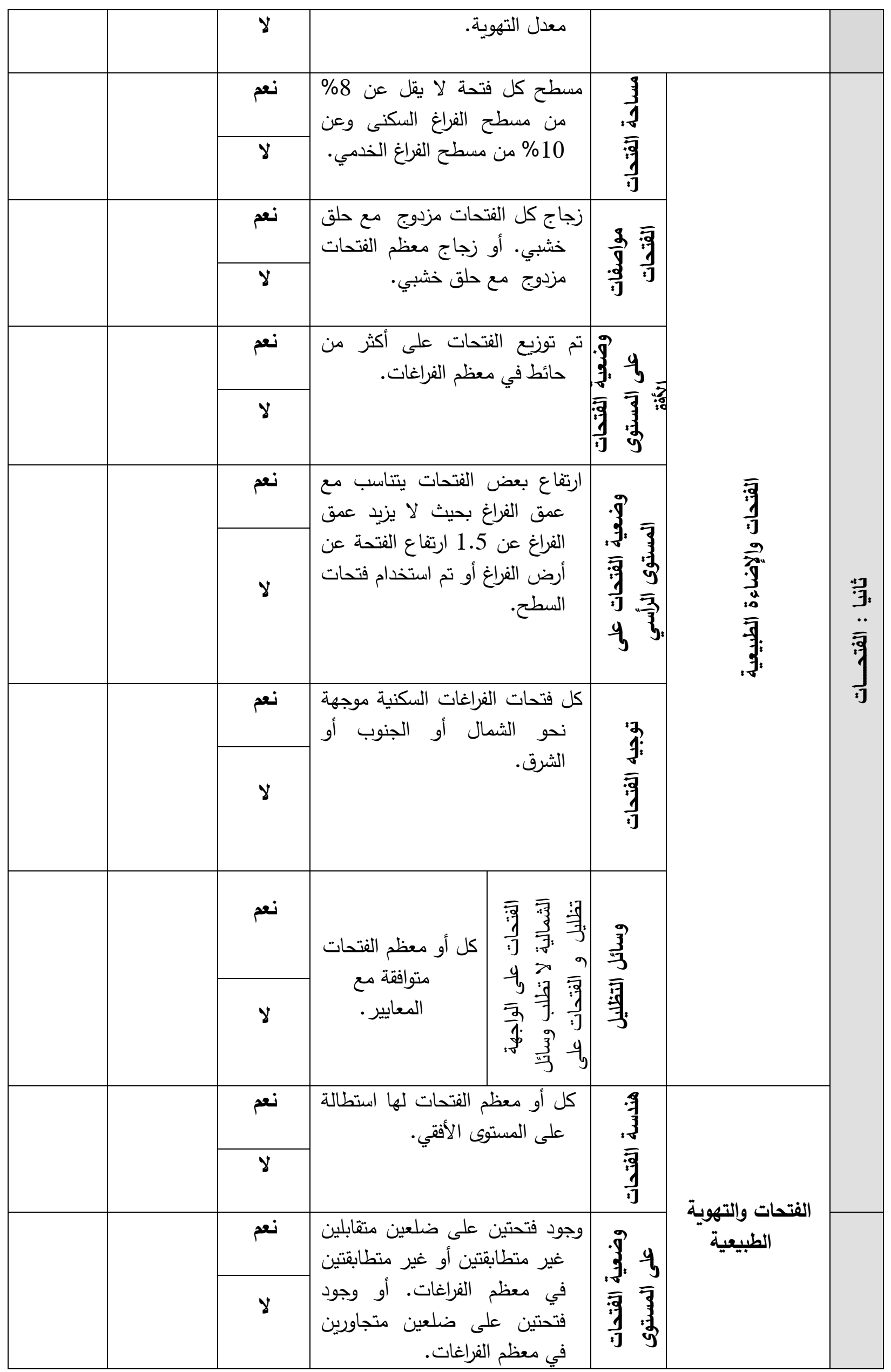




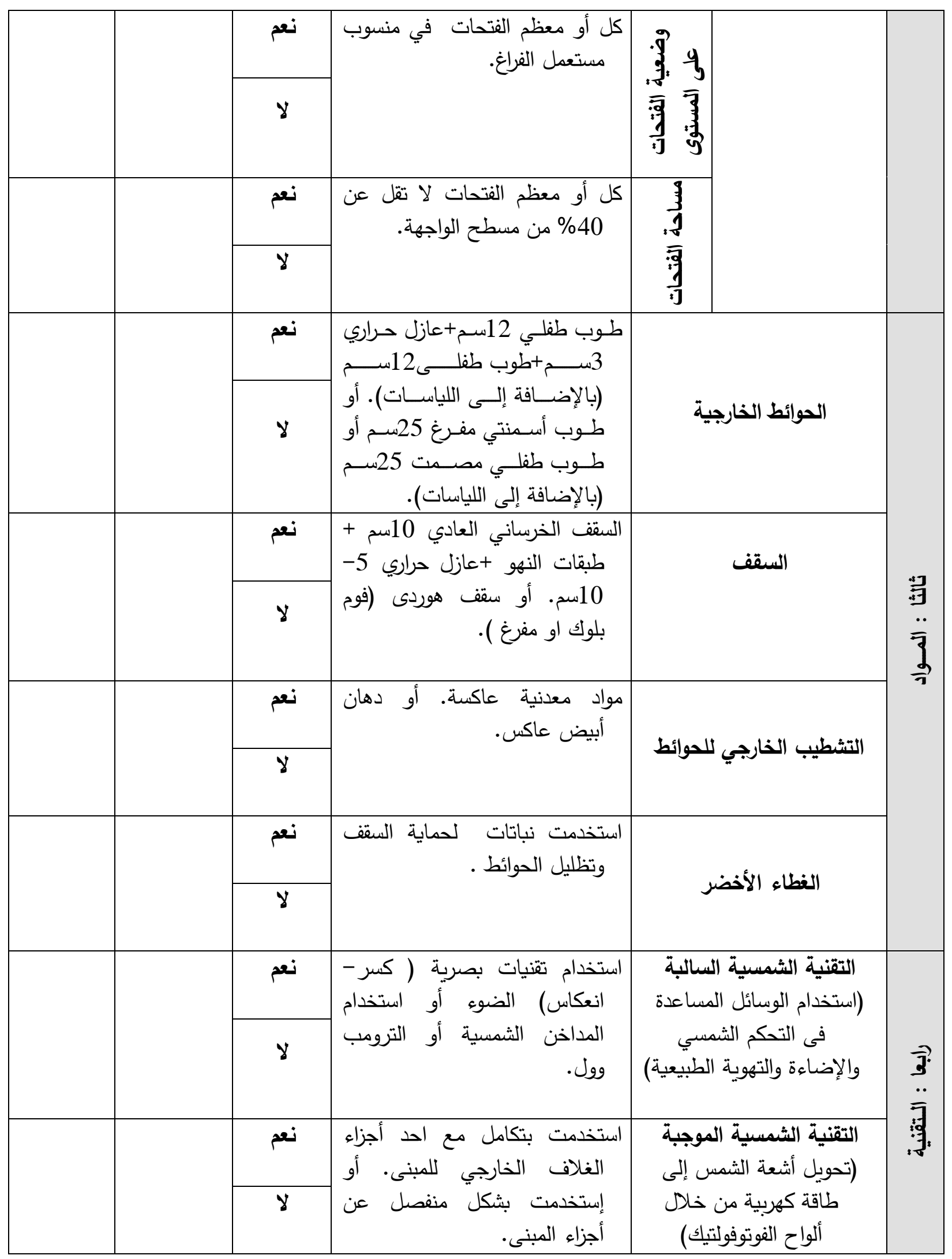

5-4-5 مميزات هذه الاداة :-

• التقييم يعتمد على إدخال بيانات التصميم بشكل تقنى من خلادل التهل إختيار أحد البدائل ولذلك فهو لا يحتاج إلى متخصصين للقيام

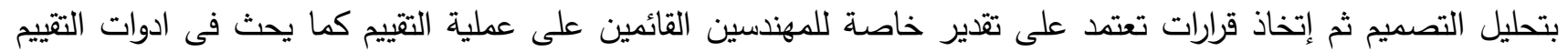
السابق ذكرها. • لا يتطلب إستخدام تلك الاداة الرجوع إلى أى مرجعيات للمساعدة فى عملية التقييم كما يحدث فيأداة التقييم المصرية والتى لئى يتطلب إستخدامها الرجوع إلى كود الطاقة المصرى وهو نظام غير مبسط يحتاج إلى متخصصين الفين متدربين . 


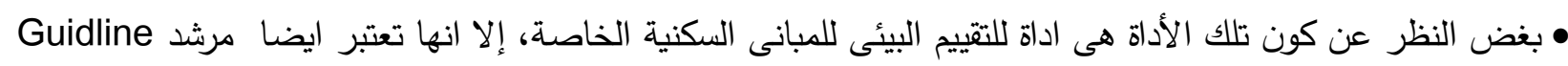

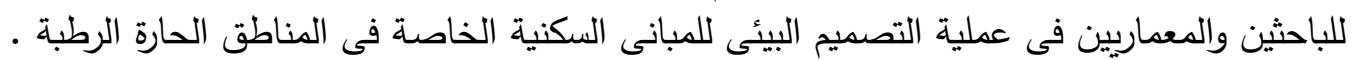

6- الخلاصــة

أثبت البحث من خلا التحليل أن أدوات التثييم البيئي للمباني المستنبطة خارج مصر لا يصلح إستخدامها فى تصنيف وتقييم

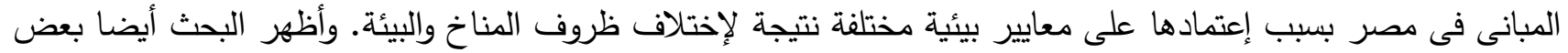

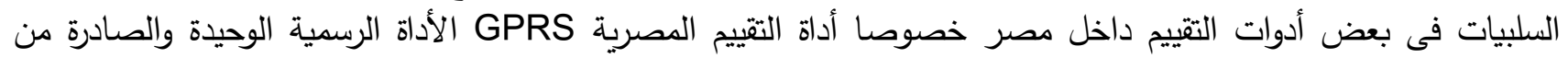
المركز القومي بحوث الإسكان والبناء المصري، حيث وجد البحث أنها لن تحقق الهدف من البحث وهو أداة تقييم ذات آلية آلية

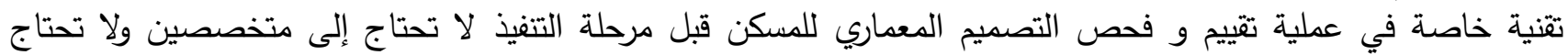

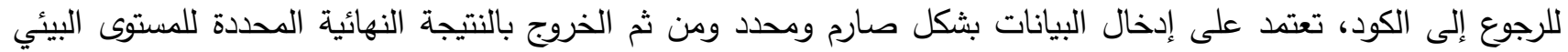

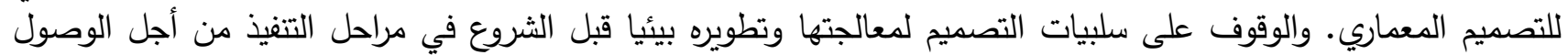

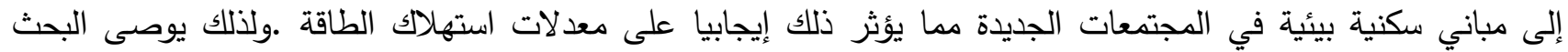

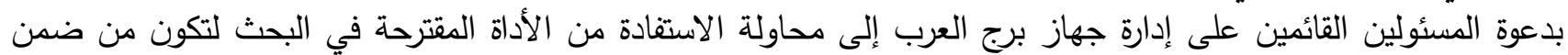

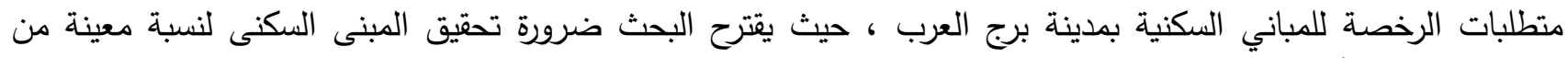

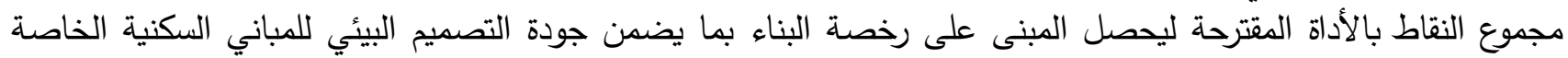

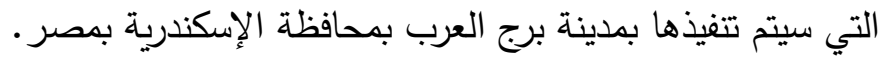

7 المراجع العربية

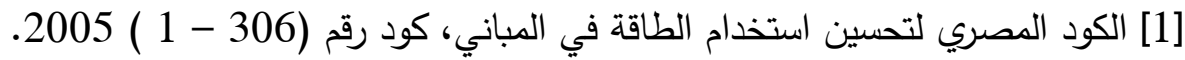
[2] د/أسامة عبد النبي قنبرد، 2005، " استدامة المناطق السكنية بالمجتمعات الحضرية الجديدة بإقليم القاهرة الكبرى"، رسالة

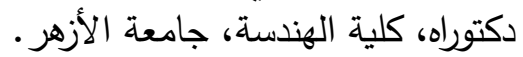

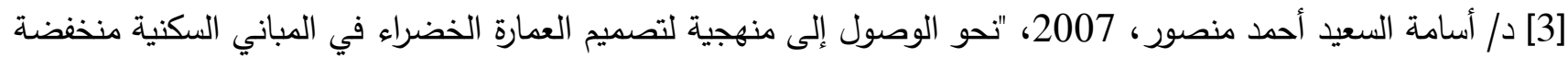
الارتفاع بالقاهرة" ، دكتوراه ، جامعة المديد عين شمس.

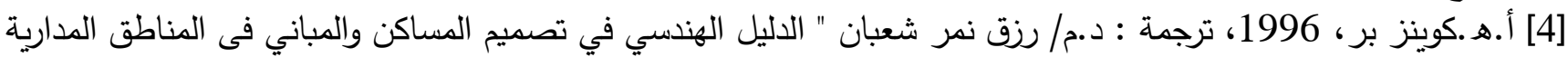

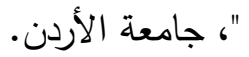

8

[5] Norbert lechner, 2008, Heating, Cooling, Lighting: Sustainable Design Methods for Architects, Wiley, Canada.

[6] G.Z.Brown, 2001; "Sun, Wind \&Light, Architectural Design Strategies ,John Wiley \& sons, Inc, Canada.

[7] Deborah Carnes Christie, 2009 Green House: The Story of a Healthy, Energy-Efficient Home, Deborah Carnes Christie, USA.

[8] Daniel E. Williams, 2007, Sustainable Design: Ecology, Architecture, and Planning, Wiley, Canada.

[9] ( World Green Building Council ) http://www.worldgbc.org (last seen in January 2014) [10] http://www.breeam.org (last seen in January 2014)

[11] (The U.S. Green Building Council) http://www.usgbc.org (last seen in January 2014)

[12] Green building Australian Council www.gbca.org.au (last seen in January 2014)

[13] Japan External Trade Organization http://www.jetro.org (last seen in January 2014)

[14] Egypt Green building Council http://www.egypt-gbc.gov.eg (last seen in January 2014)

[15] (Egyptian Ministry of Stat for Environmental affairs) http://www.eeaa.gov.eg/ (last seen in January 2014)

[16] Office of Energy Efficient and renewable Energy, Washington http://eere.energy.gov (last seen in January 2014) 